\title{
Contribution of Imagery in Retro Peritoneal Tumors in Children
}

Amine El Masloumi ${ }^{1 *}$, Christ Labretesche Gakosso ${ }^{2}$, Anass Chehboun ${ }^{3}$, Dounia Basraoui ${ }^{4}$, Hicham Jalal ${ }^{5}$

\author{
${ }_{1,2,3}$ Student in Radiology, ${ }^{4,5}$ Professor in Radiology, Radiology department, Mother and Child's Hospital, Mohammed VIth Teaching center, Cadi Ayad \\ University, Marrakesh, Morocco
}

DOI: $10.36347 /$ sjmcr.2020.v08i07.016

| Received: 08.07.2020 | Accepted: 15.07.2020 | Published: 28.07.2020

*Corresponding author: Amine El Masloumi

Abstract

Original Research Article

The retroperitoneal tumors in children represent the majority of abdominal masses child before the age of 7 years and half between 7 and 15 years. Nephroblastoma or Wilms tumor and neuroblastoma are the most common etiologies. The aim of this study is to recall the contribution of imaging methods in the diagnosis and monitoring of retroperitoneal tumors in children. It is a retrospective study conducted over a period of 10 years (from January 2010 to December 2019), 126 benign and malignant retroperitoneal tumors, explored by ultrasound in all patients and by the abdominal CT scan in (88\% of patients. All diagnostics were confirmed histologically by the examination of the surgical specimen. The average age of our patients was 8 years with a slight female predominance. We identified 75 cases of nephroblastoma (59.52\%), 38 cases of neuroblastoma $(30.15 \%), 5$ cases of SRCC (3,96 \%),4 cases of mesoblastic nephroma (3.17\%), 3 cases of pheochromocytoma (2.38\%), and a case of malignant non Hodgkinian lymphoma (Burkitt) $(0,79 \%)$. The imaging plays a vital role in the diagnosis of retroperitoneal tumors in children. Ultrasound remains the predominant method made its availability, its diagnosis and its non- radiating performance character. It allows, before the discovery of an abdominal mass, confirmed the presence of a tumor and make the differential diagnosis with other non- tumor lesions. Then comes the role of abdominal CT in second plan to confirm the ultrasound data and identify locoregional and distant as well as anatomical and vascular reporting and it also helps in cases of large tumors to determine its organ of origin and measures in the 3 spatial planes.

Keywords: Retroperitoneal tumors - Child - Ultrasound - CT.

Copyright @ 2020: This is an open-access article distributed under the terms of the Creative Commons Attribution license which permits unrestricted use, distribution, and reproduction in any medium for non-commercial use (NonCommercial, or CC-BY-NC) provided the original author and source are credited.

\section{INTRODUCTION}

Retroperitoneal tumors in children are a common pathology in pediatric oncology since they are in the majority of malignant cases [1]. So, the discovery of a retroperitoneal tumor represents a serious event for the practitioner as for the family and immediately raises the etiological diagnosis, which requires urgent care [2]. Clinical manifestations vary depending on the topography and benign or malignant character; the tumor may be asymptomatic or revealed by complications. Imaging and biology remain an important part of the diagnostic process, not to mention the role of surgery, which contributes to both diagnosis and treatment. The etiological diagnosis depends on the age of the patient and the site of the tumour. The etiological diagnosis depends on the age of the patient and the site of the tumour. However, more often than not, only anatomopathology provides the diagnosis of certainty. The classic means of imaging a retroperitoneal tumor in children are represented by ultrasound, CT, MRI [3, 4]. This retrospective study aims to review the practice of imaging retroperitoneal tumors. The objectives of our study are: Determine the indications, advantages and limits of each imaging technic. Review the radiological semiology of the various tumors observed in our patients.

\section{Materials and Methods}

This study is retrospective, relating to 126 cases of retroperitoneal tumors collected in the pediatric radiology, pediatric oncology and infant surgery department B of the Mohammed VI Hospital, of Marrakech over a period of 8 years, going from January 2010 to December 2019.

\section{Inclusion criteria}

The patients recruited in this study are those who have radiological and ultrasound documents in their files. Cases with histological confirmation and whose age is less than 15 years.

\section{Exclusion criteria}

Diagnosis is made outside the study period. Unusable records. Patients over the age of 15 . 


\section{RESULTS}

Between January 2010 and December 2019, 126 cases of retroperitoneal tumours were collected. The distribution of tumours by histological type is detailed in Figure I. The prevalence of malignant tumours can be noted, including a preponderance of nephroblastoma $(59.52 \%)$; followed by neuroblastoma $(30.15 \%)$, then clear cell renal sarcoma $(3.96 \%)$ and Burkitt's lymphoma $(0.79 \%)$. In contrast to benign tumours of which only 5 cases have been reported such as mesoblastic nephrome and pheochromocytome which represent $3.17 \%$ and $2.38 \%$ respectively. The age of the patients was between 1 month and 14 years with an average age of 7 years. The age group most affected was between 2 and 5 years of age; It accounts for $57 \%$ of cases; followed by the 5-10 age group.

The gender distribution shows a slight female predominance with a male-female ratio of 0.85 (58/68). The clinical picture was typical; thus the abdominal mass was the most common reason for consultation in our series; it was found in 68 patients (54\%); abdominal distension was noted in 45 patients or $35.7 \%$, as well as abdominal pain that was found in 35 patients or $27.27 \%$, followed by alteration of the general condition that was found in 25 patients 19.8\%; hyper blood pressure and fever in $6.3 \%$ and $3.17 \%$ of cases respectively and hematuria in 3 cases and finally only one case was discovered incidentally.

The abdominal examination had objectified the presence of an abdominal mass as the main physical sign present in 92 patients, it was hard, fixed, firm, painless and variable seat.

Hepatomegaly was objectified in 8 patients and abdominal sensitivity in 38 patients, sub-skin nodules 3 patients and temporal mass in 2 cases and diffuse bone pain in a single patient.

The dosage of urinary catecholamines, vanylmandilic acid, homovanilic acid and urinary dopamine, was requested in 36 cases in which neuroblastoma was suspected and in both cases in which pheochromocytom was suspected. The myelogram was requested as part of the extension check in 27 cases in which neuroblastoma was diagnosed and in only one case in which Burkitt lymphoma was suspected. Myelogram results were normal in 19 cases of neuroblastoma, as well as in the case of Burkitt lymphoma, however there was a medullary invasion by extra-hematopoietic cells in 8 cases of neuroblastoma.

\section{Imaging data}

In our series, a number of radiological examinations were conducted. Indeed, for the following pathological groups we note:

\section{Abdominal ultrasound}

Abdominal ultrasound remains the basic radiological examination and the first investigation in abdominal mass exploration. In our series, it was requested from all our patients.

Abdominal ultrasound objectified a heterogeneous echogenic retroperitoneal tumor in almost all cases, unilateral in $97.64 \%$ of cases and bilateral in $2.35 \%$. At the expense of the right kidney in $26 \%$ of cases, the left kidney in $38 \%$ cases, the right adrenal in $14 \%$ of cases, the left adrenal in $17 \%$ and the para-vertebral space in $3 \%$ of cases.

Abdominal ultrasound remains the basic radiological examination and the first investigation in abdominal mass exploration. In our series, it was requested from all our patients.

Abdominal ultrasound objectified a heterogeneous echogenic retroperitoneal tumor in almost all cases, unilateral in $97.64 \%$ of cases and bilateral in $2.35 \%$. At the expense of the right kidney in $26 \%$ of cases, the left kidney in $38 \%$ cases, the right adrenal in $14 \%$ of cases, the left adrenal in $17 \%$ and the para-vertebral space in $3 \%$ of cases.

Nephroblastoma: was of unilateral focal uni siege in 73 cases, bilateral in two cases. The tumor was heterogeneous echogenic in all cases, calcifications in 18 cases, cystic zones in 68 cases and necrosis zones in 43 of the cases. The nephroblastoma was regularly voluminous and well limited in $100 \%$ of cases; the renal arterial pedicule is usually repressed by the tumor. The average tumor volume of $1890 \mathrm{ml}$. Invasion of the lower vena cava and renal veins was objectified in three patients. Neighbourhood organs were found in $24.6 \%$ of cases. The spur sign was found in 11 patients or $18.2 \%$. Intra-peritoneal effusion was found in 9 cases.

Neuroblastoma: Neuroblastoma was right adrenal seat in 10 cases or $38.46 \%$, sat at the level of the left adrenal in 19 cases, 5 cases of bilateral neuroblastoma 4 cases of paravertebral seat. It was heterogeneous echogenic in all cases, seat of hypoechogen zones corresponding to cystic zones and was little vascularized to the Doppler color.

It had hyperechogen zones related to calcifications in $54.7 \%$ of cases. Tumor limits were irregular in the majority of cases, $74.6 \%$ and regular in $25.4 \%$ of cases. We found a refoulement of the neighbourhood organs in 12 cases with exceeding the median line in 6 cases and a refoulement of the renal pedicule in 4 cases.

Liver metastases found in 17 cases in the form of multiple heterogeneous hyperechogenous rounded nodular formations. 
Adenopathies were found in 6 cases and peritoneal effusion in 4 cases.

Clear cell renal sarcoma: Ultrasound objectified a very limited tissue mass, heterogeneous echogen in $100 \%$ of cases, sitting in necrotic and cystic zones in $75.4 \%$ of cases and calcifications in a 2 case. The ultrasound also revealed an overshoot of the middle line with refoulement of the liver and the lower cellar vein, but this one was permeable. It also highlighted two secondary liver lesion processes in a single case, in all cases; no ultrasound elements could formally differentiate clear cell renal sarcoma from the nephroblastoma.

Burkitt lymphoma: The unique case of Burkitt lymphoma in our series presented ultrasound by a very limited hypoechogen right adrenal mass measuring $56 \times 42 \mathrm{~mm}$ associated with para-vertebral retroperitoneal ganglionary magmas, with a significant clumping, infiltration and diffuse thickening of digestive handles.

Multiple and diffuse masses throughout the entire abdominal-pelvic cavity, homogeneous hypoechogenic inter-coves of lobulated contours were also highlighted.

Ultrasound also revealed a finely echogenic peritoneal effusion of medium abundance.

\section{Mesoblastic nephroma}

\section{The ultrasound aspect of the mesoblastic nephrome} in our series was

Case 1: A very limited heterogeneous echogenic mass vascularized to the doppler and appeared to be at the expense of the lower pole of the left kidney with individualization of the spur sign. This mass was responsible for homolateral pyelocalicial dilation.

Case 2: a huge partitioned tissue and cystic mass, heterogeneous echogen that extended from the left hypochondrage to the pelvis, extending beyond the middle line.

Case 3 and 4: heterogeneous right lower right inverterous polar mass.

\section{The pheochromocytoma}

Case 1: a coarsely oval mass well-limited measuring at the level of the left renal lodge of heterogeneous echogenic structure, with an area of anechogen central necrosis.

Case 2: a grossly oval mass well limited to the right renal lodge of heterogeneous echogenic structure, with an area of anechogen central necrosis.
Case 3: a very limited oval mass, echogenic, heterogeneous.

\section{Abdominal CT scans \\ CT was performed in 111 patients in our} series, divided into 68 cases of nephroblastoma, 32 cases of neuroblastoma, 4 cases of clear cell renal sarcoma, 3 cases of mesoblastic nephrome, 3 cases of pheochromocytom and one case of lymphoma. (Table 3)

Burkitt lymphoma CT scan a well-limited and homogeneous right adrenal hypodense mass, not enhancing by contrast, measuring 56x $42 \mathrm{~mm}$ without calcifications or necrosis zones, associated with $38 \mathrm{~mm}$ small liver hile adenopathy, associated with adenopathy of the hepatic hile axis, clustered small handles, moderate right hydronephrosis and low-abundance ascites.

Locoregional extension of the different tumors: The locoregional extension of the different tumors is mainly vascular (large vessels and the renal pedicule); for nephroblastoma a large vessels and renal cave vein were found in $16.66 \%$ and $21.42 \%$ respectively and a 1 case of thrombosis of the lower vena cava with extension to the right atrium.

For neuroblastoma, vascular extension is much more pronounced compared to nephroblastoma. However Pepper syndrome (liver metastases) was found in $26.92 \%$ of cases.

\section{Anatomopathological data}

In our study, an anatomopathological study of the operating room was done in all patients operated on. It confirmed the diagnosis suspected radiologically for the majority of cases and reconsidered the diagnosis for other cases. The distribution of cases based on anatomopathological outcomes is summarized in the diagram (Figure 1).

\section{DiscuSSION}

\section{Nephroblastoma}

a. Abdominal ultrasound

It highlights a mass that, in most cases, is large, very limited. The structure is generally echogenic, more or less heterogeneous with quite frequent trans-sound ranges, corresponding to cystic or necrotic zones. The extension of healthy renal parenchyma gradually connecting to the mass gives the sign of the spur; the kidney may be invisible in the case of a large mass. Sometimes, on the contrary, the kidney appears normal and the tumour appears to grow on its cortical in case of exorenally developing nephroblastoma. In these cases, the continuity between the tumour and the renal parenchyma must be shown [5-7]. 
The assessment of the volume of the tumour is essential for treatment and prognosis unlike neuroblastoma, nephroblastoma does not engaine the vessels, but represses them. The doppler can be used to look for vascular thrombosis. Indeed, the subferensional subnement vein needs to be analyzed, in search of an endoluminal thrombus [8].

In addition, some ultrasound aspects may simulate nephroblastoma. Infection in the form of pseudo-tumor pyelonephritis, abscess, or xanthogranulomatous pyelonephritis. However, the comparison with the data of the history, the clinic and the biology guides the diagnosis [9].

\section{b. Abdominal CT}

Abdominal CT is performed if the intra-renal starting point is difficult to confirm in ultrasound, in case of suspected tumor rupture, bilateral tumor or in preoperative period if it was not done initially. The mass appears solid heterogeneous; intra-tumor calcifications and fatty islands are sometimes visible. This heterogeneity is reinforced by the post-injection injection of contrast product $[5,10,11]$.

The CT scan allows, with more precision than ultrasound, to answer certain questions: extension to the excretory pathways, lymph node damage, perrenal fat and especially controlal kidney disease. CT scans also allow for a more reproducible volumetric assessment than ultrasound.

At the end, the CT must currently make it possible to establish a sufficient vascular mapping in preoperative assessment, at the request of the surgeon.

\section{c. Abdominal MRI}

In $\mathrm{T} 1$ weighting, the mass has weaker signal than the renal parenchyma, with loss of visibility of the pyramids; in T2 weighting, the tumor signal becomes intense, more difficult to dissociate from healthy parenchyma. The heterogeity of the mass also appears in MRI. The examination also meetsthe objectives of the abdominal check-up and in particular the damage to the vena cava, but does not allow lung evaluation [5].

\section{Neuroblastoma}

\section{a) Abdominal ultrasound}

Ultrasound shows an independant mass of the kidney, echogenic, heterogeneous, with hyperechogenic zones in connection with calcifications. The existence of trans-sonic ranges is less frequent than in the context of Wilms's tumor. However, predominantly cystic tumors do exist. Most often the tumor is ill-defined; it is therefore difficult to specifyits size and limits and dissociates it from lymphadenopathy. It includes the arterial axes and this is very suggestive to the diagnosis. Morphological ultrasound can be supplemented by the evaluation of vascular reports by doppler technic.
Ultrasound also makes it possible to assess relationships with neighboring organs $[12,13]$.

\section{b. Abdominal CT}

The nephroblastoma presents as a mass of tissue density, containing fine and irregular calcifications. It is slightly enhanced by the injection of contrast product,associated or not with locoregional adenopathies and encompassing vascular axes. The CT allows a concomitant study of bone damage in the bone window and establishes a locoregional extension assessment. It specifies the node extensions to the posterior infra-mediatinal space, to the lombo-aortic chains and more rarely iliac [14]. The intrarachidian extensions of paravertebral hourglass neuroblastomas through the conjugation holes are well demonstrated by the CT after intravenous injection of contrast product; these intraspinal tumor extensions appear hyperdense, sometimes calcified.

\section{c. Abdominal MRI}

MRI allows an excellent assessment whatever the size of the tumor. In T1, the neuroblastoma presents a signal superior to that of the muscle, in $\mathrm{T} 2$ a relative hypersignal. Fine tumor calcifications are not identified. The osteomedullary localizations cause a relative hyposignal in $\mathrm{T} 1$ and a hypersignal in $\mathrm{T} 2$ of the bone marrow. The sensitivity of MRI in exploration osteomedullary involvement is high, but it does not allow a global study of the skeleton $[15,16]$.

\section{Clear cell renal sarcoma \\ a. Abdominal ultrasound}

Ultrasound confims the renal origin of the tumor which usually appears in the form of a bulky mass comprising areas of necrosis and especially cystis. The Doppler assesses the permeability of the inferior vena cava and the extension to the renal vena, which may be the site of a thrombus in 5\% of cases [17].

\section{b. Abdominal CT}

It shows the presence of an uncapsulated mass, of heterogeneous density slightly lower than that of the renal parenchhyma and of large size which may include hemorrhagic zones. Otherwise calcifications are unusual and have only been encountered in our series in one case [18].

\section{c. Abdominal MRI}

MRI if performed analyzes with great precison the vascular relationships of the mass. In T1, the tumor has a weak signal compared to the renal parenchyma. In $\mathrm{T} 2$, the signal becomes more intense and difficult to differentiate from healthy renal parenchyma [19].

\section{Mesoblastic nephroma a. Ultrasound}

The tumor appears more or less heteregeneous. The presence around the tumor of a hypoechogen ring in wich a doppler signal is identifie dis very suggestive 
of a Bolande tumor. This criterion is not specific to the mesoblastic nephroma since it is found in other tumor types, but it would be a factor directing towards the benign nature of the tumor. Ultrasound also helps to better evaluate a cystic or necrotic component of the tumor that is more common in cases of mesoblastic cell nephroma [20].

\section{b. Abdominale CT}

The tumor appears as a uniform mass, slightly re-raising after injection of the contrast product, except in the periphery. Intra-tumor hemorrhage is better detected in CT than on ultrasound. It also allows to carry out a balance of lung and abdominal extension. In MRI, the tumor appears hypo intese in T1 before and after gadolinium injection [20].

\section{c. Abdominal MRI}

MRI showed a adrenal proess in hyposignal T1 and hypersignal T2 taking strong contrast after gadolinium injection with sometimes necrosis zones [21].

\section{Burkitt lymphoma}

\section{a. Abdominal ultrasound}

The abdominal ultrasound allows a good study of the intra and retroperitoneal node chains and the analysis of mesenteric locations, it also allows to recognize a complicationsuch as intestinal sufferting, tumor puncture under ultrasound makes it possible to make the diagnosis. Frequently, adrenal lymphoma reults in a large mass more or less well limited destroying the adrenal; it is often homogeneous but can be heterogeneous especially in cases of large mass [22].

\section{b. Abdominal CT}

The advantage of the CT is to provide precise objective and easily reproducible and communicable documents, allowinga certain quantification of the lesions. Excellent study of lymph node chains and visceral damage. In our series, the $\mathrm{CT}$ was used to evoke the doagnosis of lymphoma first, in fronty of a right adrenal mass with liver hile adenopathies and ascite, associated with a small handles [23].

\section{Pheochromocytoma \\ a. Ultrasound}

The usual appearance of pheochromocytoma on ultrasound is a coarsely oval and well-limited heteregeneous mass with double hypo and hyperechogenic components, sometimes with anechogen, necrotic or cystic zones. It may alson contain calcifications [24].

\section{b. Abdominal CT}

An adrenal mass viewed on a $\mathrm{CT}$ scan will be assessed by measuring the spontaneous density (before injection), as well as its evolution in the early and late time, after injection. Her size, its homogeneity and its vascularisation will thus be determined. In our observation, the CT showed well limited oval lesions spontaneously hypodense in spontaneous contrast, intense and peripheral enhancement after injection of contrast medium and delimiting an area of central necrosis in one case and associated with discreet infiltration of the neighborhood fat.

\section{c. Abdominal MRI}

The MRI showed an adrenal process in hyposignal $\mathrm{T} 1$ and hypersignal $\mathrm{T} 2$ taking strongly the contrast after injection of the gadolinium with sometimes, areas of necrosis. In our series, no MRI was done. [21].

\section{Conclusion}

Any radiologist can be confronted in his usual exercise with the discovery and therefore with the initial assessment of a retroperitoneal mass in a child. Its first objective will be to specify with certainty the origin of the renal or extrarenal mass, then to affirm its tumor nature. Ultrasound is in the vast majority of cases sufficient. When it is obviously a tumor, the pretherapeutic assessment must be carried out in agreement with the pediatric oncology team which will take charge of the child and the realization of a CT or an MRI will be contributory only if it is integrated in a team reflection. The diagnostic diagnosis issue is important since most of these malignant tumors, from the age of 6 months, benefit from specific preoperative chemotherapy, established on imging data, biological markers (catecholamines, dopamine, and specific enolase neuron) or after diagnostic percutaneous puncture. The 2 essential elements for diagnosis are the ultrasound data which in most cases makes it possible to determine the renal or extrarenal origin of the tumor and the age of the discovery. 


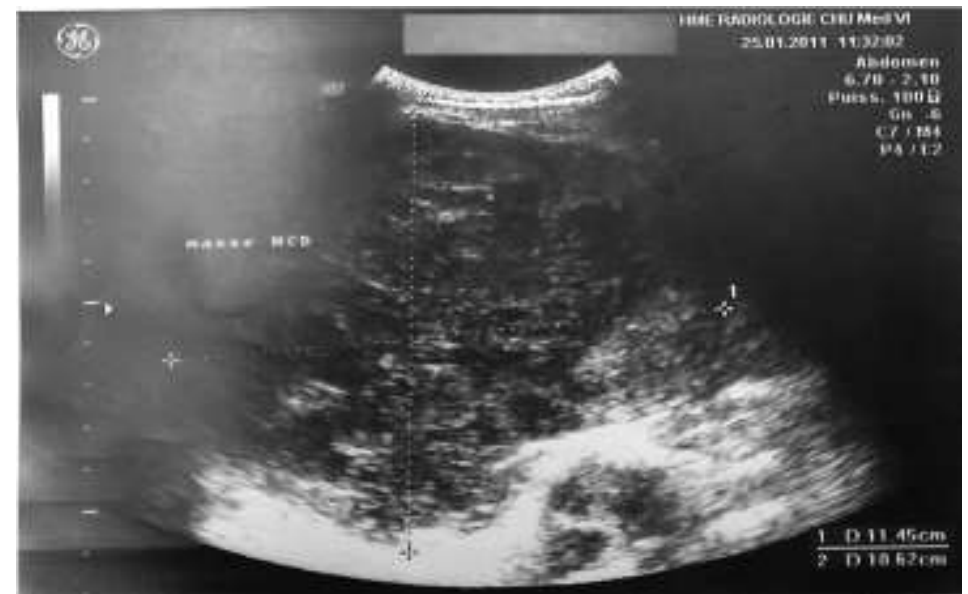

Fig-1: Ultrasound aspect of right nephroblastoma: large tissue mass located at the HCD and the right flank, echogenic, heterogeneous, with multiple cystic zones

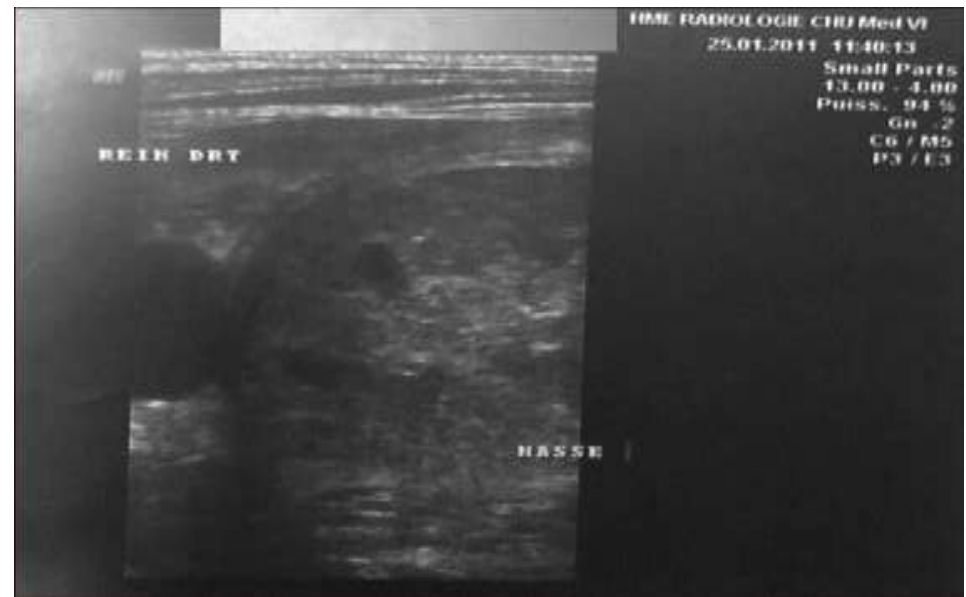

Fig-2: Right nephroblastoma with individualization of the spur sign which confirmed the renal origin of the mass

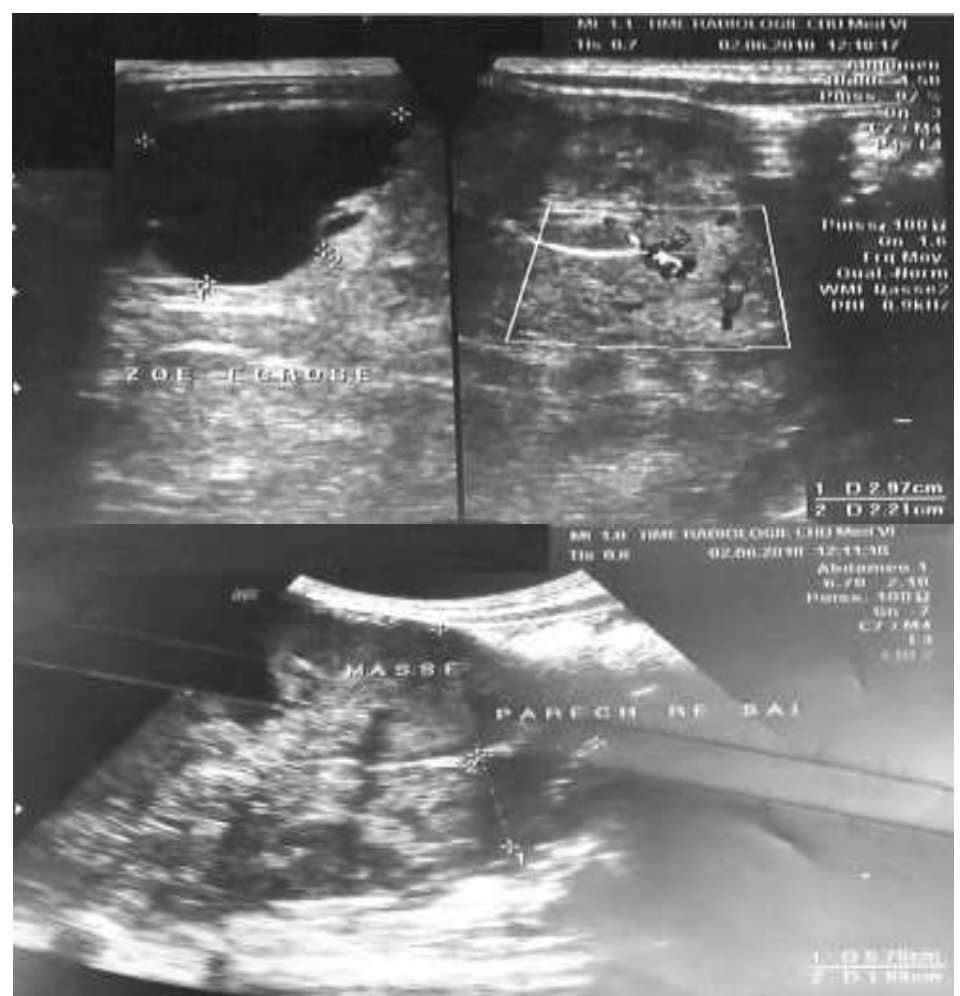

Fig-3: Right nephroblastoma: bulky tissue mass, oval, wellimited, at the expense of the right kidney, heterogeneous, vascularizedwith Doppler with large anechogenic, cystic or necrotic areas 


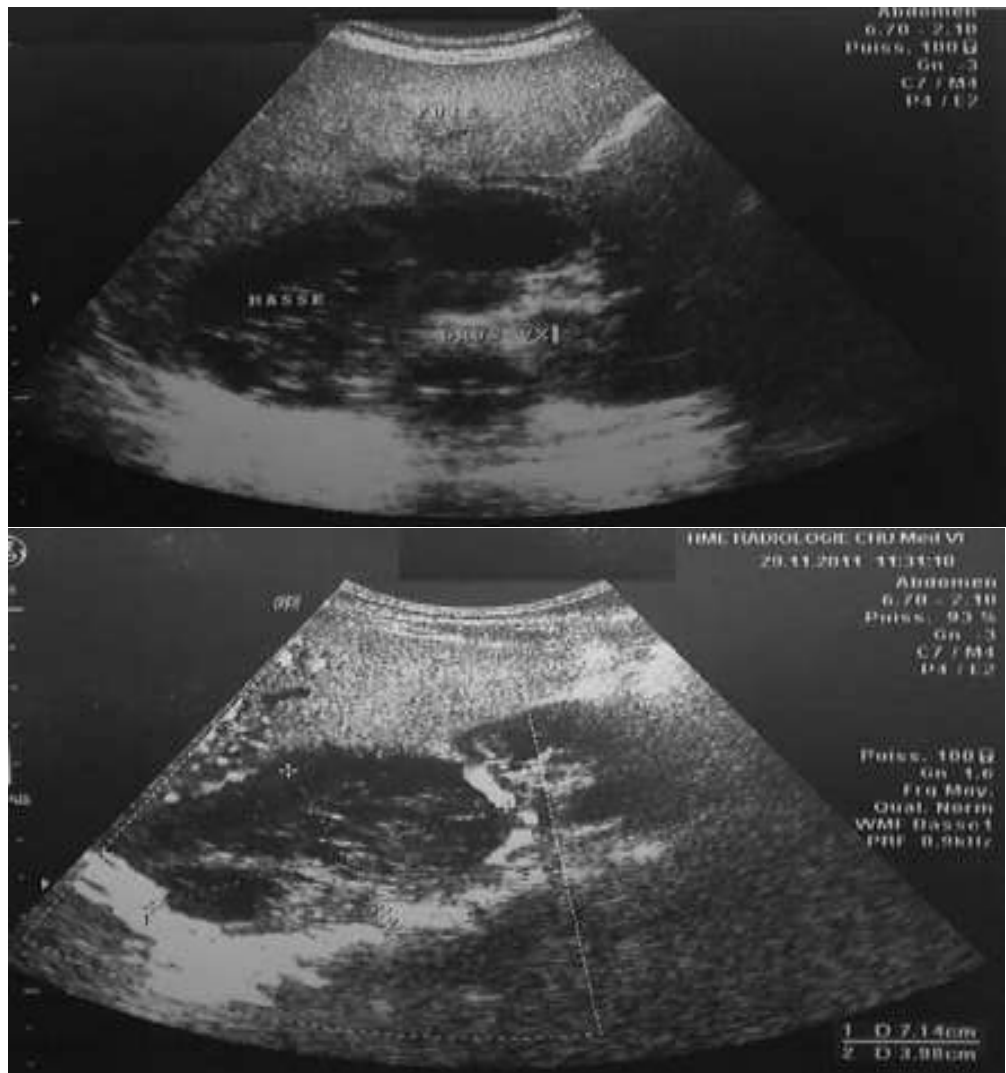

Fig-4: Ultrasound aspect of right adrenal neuroblastoma shows: mixed tissue and oval and well limited cystic mass heterogeneous hypoechoic including and driving back the large vessels

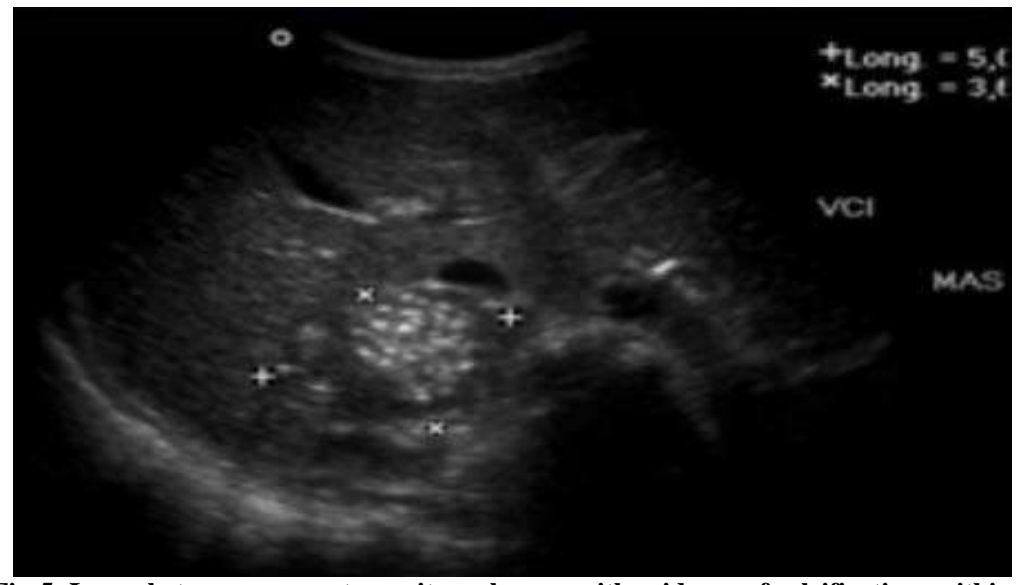

Fig-5: Large heterogeneousretroperitoneal mass, with evidence of calcifications within it

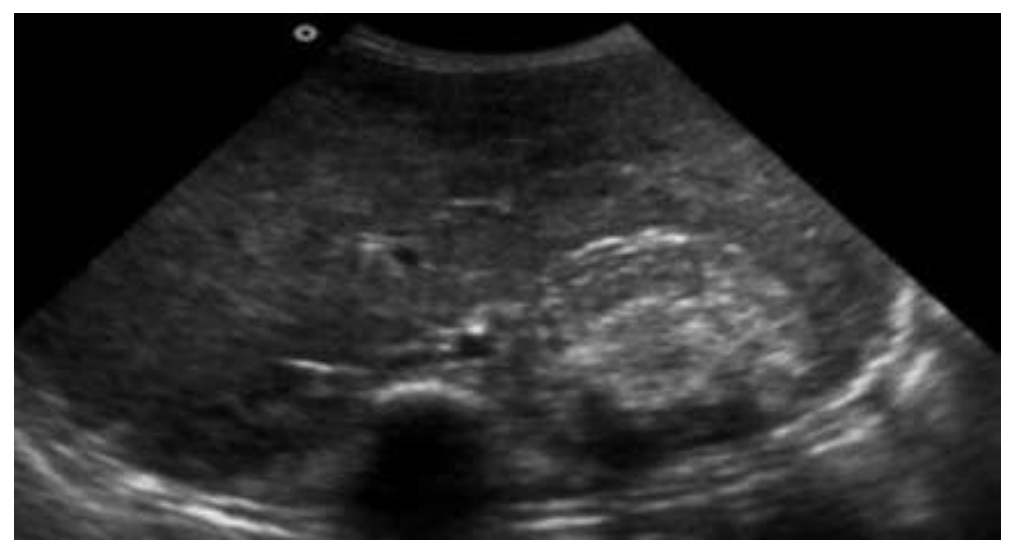

Fig-6: Ultrasound images showing a right adrenal mass associated with agglutination and thickening of the intestinal loops as well as mediumabundant fluid effusion related to lymphoma 


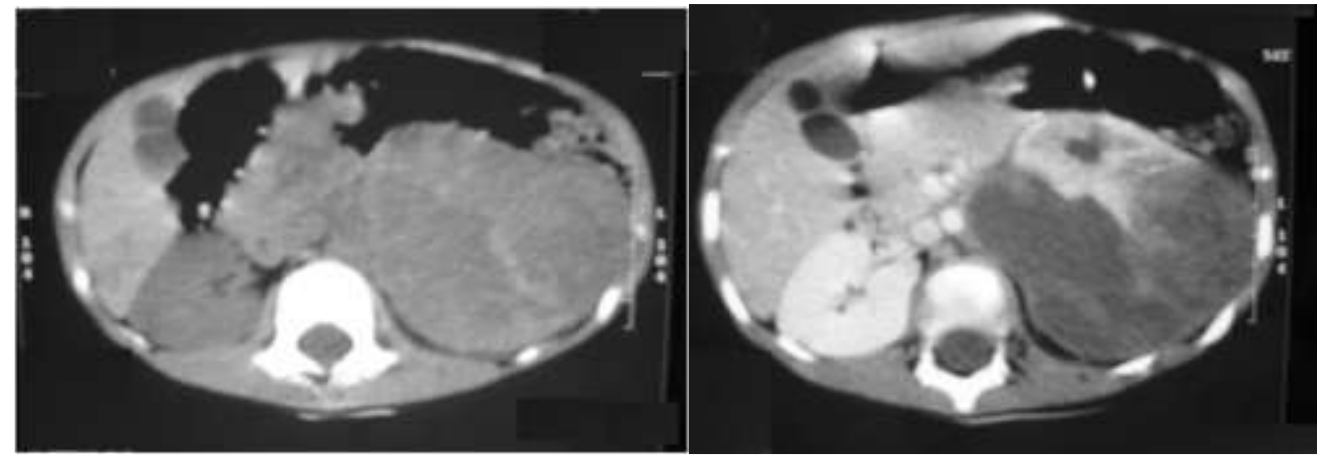

Fig-7: CT in axial sections without and with injection of iodinated contrast product with coronal reconstructions: cystic left renal mass: nephroblastoma

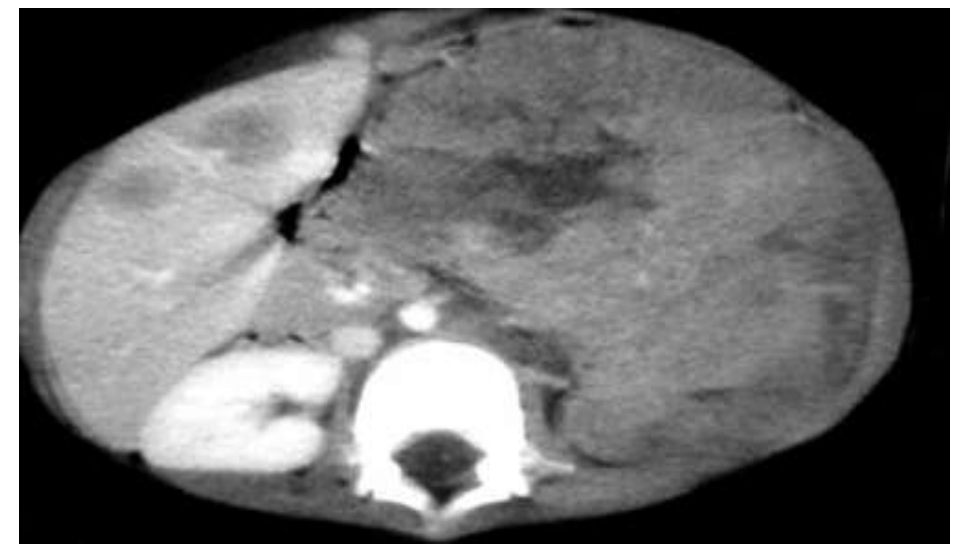

Fig-8: CT in axial plan after injection iodinated contrast product shows heterogeneous left renal mass and moderated by the contrast product crossing the midline with hepatic metastases: CCRS

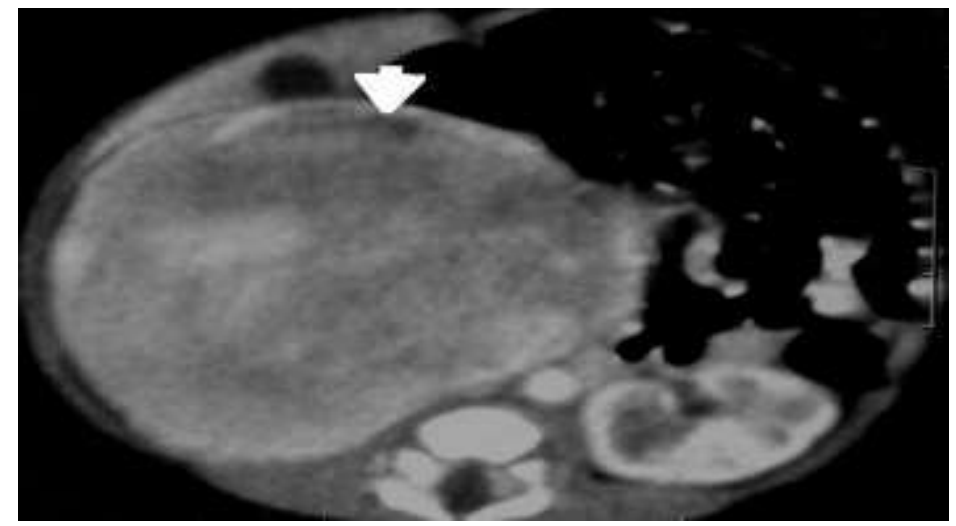

Fig-9: CT in axial plan after injection of iodized contrast product shows a right renal mass enhanced by the contrast product with sign of the spur: mesoblastic nephroma in an infant

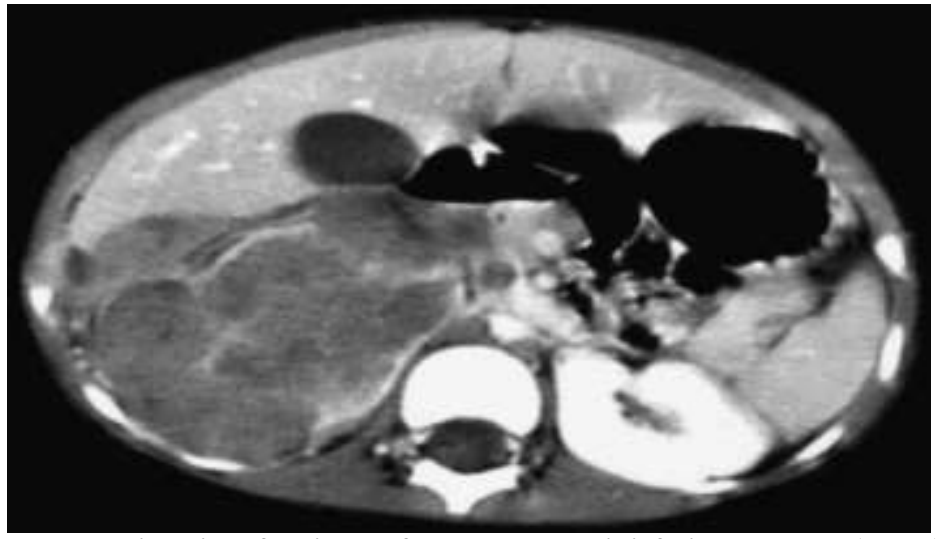

Fig-10: Crossing of the renal capsule and invasion of peri-renal fat and thrombosis inferior vena cava (arrow) in a 4-year-old girl with right nephroblastoma 


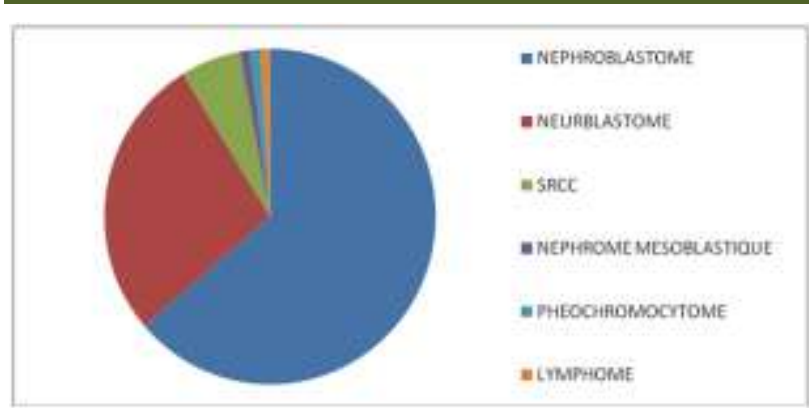

Fig-11: Distribution of cases according to anatomopathological results

\section{REFERENCES}

1. Yang DM, Jung DH, Kim H, Kang JH, Kim SH, Kim JH, Hwang HY. Retroperitoneal cystic masses: CT, clinical, and pathologic findings and literature review. Radiographics. 2004 Sep;24(5):1353-65.

2. Merran S, Karila-Cohen P, Vieillefond A. Tumeurs rétropéritonéales primitives de l'adulte. Journal de Radiologie. 2004 Feb 1;85(2):252-64.

3. Rajiah P, Sinha R, Cuevas C, Dubinsky TJ, Bush Jr WH, Kolokythas O. Imaging of uncommon retroperitoneal masses. Radiographics. 2011 Jul;31(4):949-76.

4. Nishino M, Hayakawa K, Minami M, Yamamoto A, Ueda $\mathrm{H}$, Takasu $\mathrm{K}$. Primary retroperitoneal neoplasms: CT and MR imaging findings with anatomic and pathologic diagnostic clues. Radiographics. 2003 Jan;23(1):45-57.

5. Salem R, Gaha M, Jellali M A, Zrig A, Harzallah $\mathrm{W}$, Manari W, Caractéristiques sémiologiques des néphroblastomes en imagerie en coupe : rapport d'une série de 101A. Pedia. $2014 ; 21(5): 601$

6. Sahnoun L, Ksia L, Mansour WB, Hadhri R, Mosbahi S, Hammedi, Maazoun K, Krichene. ITrois observation de néphrome mésoblastique. African. J. Urolo. 2014; 20 :161-64

7. Tricaud E, Cornelis F, Havez M, Lippa L, Hubrecht R, Deminière C, Grenier. N Apport de l'IRM de diffusion dans le diagnostic de lymphome surrénalien unilatéral J. Radiol. 2010;91:1310-2

8. Moumou H, Ouahab J, Benayada B, Latib R, Jroundi L, Chami L, Imageriedes lymphomes à localisation thoraco-abdominalesJ.Radiol.2009; 90(10) :1556

9. Squalli Houssaini A, Dafiri R. Tumeurs solides malignes du rein chez l'enfant: série de 64 casJ. radiol.2008; $89: 1623$.

10. Togo $\mathrm{B}$. Le néphroblastome à l'unité d'oncologie pédiatrique de l'hôpital Gabriel Touré.CarcinolProt Afrique. $2010 ; 9(10): 8-11$
11. Park JR, Eggert A, Caron H. Neuroblastoma: Biology, Prognosis, and Treatment.PediatricClinics of NorthAmerica. 2008; 55 :97-120.

12. Hirata T, Tatara H, Zaizen Y. Role of ultrasound in managing neuroblastoma detected by mass screening : a proposed ultrasonographic grading for children withneuroblastoma.J Clin Ultrasound. 1995;23:305-13

13. Beierwaltes WH. Adrenal scanning In. Textbook of Nuclear Medecine: Clinical applications.Rocha AFG Arbet JC édit Philadelphia. 1979.

14. Kacar A, Paker I, Akcoren Z.Solid tumors in Turkish children:a multicenter study. World.Journal pediatr. 2013; 9(1) :25-31.

15. Moujahid R, Kisra M. Prises-en charge du Neuroblastome abdominal chez l'enfant 2011 (à propos de 145 cas).ThèseDoctoratmédecineFès. $2011 n^{\circ} 68$

16. Keikhaei B, Pedram M, Popak B. Signs and symptoms of Neuroblastoma. J. Medicine and Medical Sci 2012; 3(4): 243-246.

17. Rubie H. Neuroblastome. EMC, pédiatrie, 4-100-E80, 2001, 12.Elmouhadi. S, Allali. N, Dafiri. R Apport de l'imagerie dans le sarcome rénal à cellules claires chez l'enfant J.radiol. 2006; 87(10) $: 154$

18. Elmouhadi S, Allali N, Dafiri. RApport de l'imagerie dans le sarcome rénal à cellules claires chez l'enfantJ.radiol. 2006;87(10):1545

19. Salam S, Zerktouni I, Ferram N, Hammoumi Z, Alzemmouri M, Sibai $\mathrm{H}$ L. OuzidaneTumeursrénales non wilms chez l'enfant (étude monocentrique de 11 cas) Rev.Marocain de cancer. 2011;3;(1):21-27

20. Moustapha H, Chaachoue H. BLe néphroblastome: Aspects clinico-radiologiques histologiques thérapeutiques et évolutifs (à propos de 34 cas).ThèseDoctoratmédecineFès. $2014 n^{\circ} 84$.

21. Viart L, Haraux E, Blanpainc S, Cordonnierd C, Ricardb J, Canarelli JP, Buisson. PLe néphrome mésoblastique congénital : diagnostic et prise en charge à partir d'un casP. en Urolo. 2012; 22 :18991

22. Brichon P, Bertrand. YLymphome de Burkitt révélé par invagination intestinale aigue Ann. chir. 2001;126:649-53

23. Patte C, Brugières L, TerrierLacombe J. Lymphomesmalins non hodgkiniens de l'enfantCancer de l'enfant Médecine-Sciences, Edition. 2008 Flammarion.

24. Rakototiana A, Ramorasata AC, Rakoto-Ratsimba $\mathrm{H}$, Hunald F. ATPhéochromocytome révélé par un accident vasculaire cérébral chez un enfantA. Pedia. 2008;15(10) 1531-1534. 